•研究报告・

\title{
不同生活型被子植物功能性状与基因组大小的关系
}

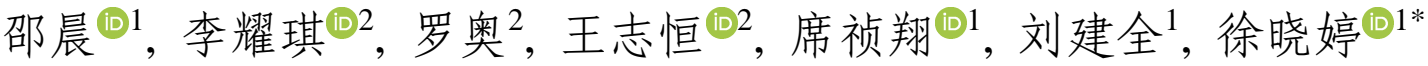

1. 四川大学生命科学学院, 生物资源与生态环境教育部重点实验室, 成都 610065; 2. 北京大学生态研究中心, 北京大学城市与环境学院, 北京大学地表过程分析与模拟教育部重点实验室, 北京 100871

摘要: 基因组大小在被子植物物种之间存在着巨大的变异，但目前对不同生活型被子植物功能性状与基因组大小的关系缺 乏统一的认识。本研究基于被子植物245科2,226属11,215个物种的基因组大小数据，探讨了不同生活型物种种子重量、最大 植株高度和叶片氮、磷含量4个功能性状与基因组大小之间的关系。结果表明, 被子植物最大植株高度和种子重量与基因组 大小间的关系在草本和木本植物中存在显著差异。草本植物最大植株高度与基因组大小的关系不显著, 但种子重量与其呈极 显著的正相关关系。木本植物最大植株高度与基因组大小显著负相关，但种子重量与其关系不显著。木本植物叶片氮含量与 基因组大小呈显著正相关，但其他生活型植物的叶片氮、磷含量与基因组大小均无显著相关性。本研究表明被子植物功能性 状与基因组大小的相关性在不同生活型间存在差异, 这为深入研究植物多种功能性状和植物生活型与基因组大小的权衡关 系在植物演化和生态适应中的作用提供了重要依据。

关键词: 基因组大小; 生活型; 叶片氮含量; 叶片磷含量; 植物功能性状; 种子重量; 最大植株高度

邵晨, 李耀琪, 罗奥, 王志恒, 席祯翔, 刘建全, 徐晓婷 (2021) 不同生活型被子植物功能性状与基因组大小的关系. 生物多样性, 29, 575-585. doi: 10.17520/biods.2020450.

Shao C, Li YQ, Luo A, Wang ZH, Xi ZX, Liu JQ, Xu XT (2021) Relationship between functional traits and genome size variation of angiosperm with different life forms. Biodiversity Science, 29, 575-585. doi: 10.17520/biods.2020450.

\section{Relationship between functional traits and genome size variation of angiosperms with different life forms}

Chen Shao ${ }^{\mathbb{D} 1}$, Yaoqi Li ${ }^{\circledR 2}$, Ao Luo ${ }^{2}$, Zhiheng Wang ${ }^{\circledR 2}$, Zhenxiang $\mathrm{Xi}^{\circledR 1}$, Jianquan $\mathrm{Liu}^{1}$, Xiaoting Xu ${ }^{(1 *}$

1 Key Laboratory for Bio-resources and Eco-environment of Ministry of Education, College of Life Sciences, Sichuan University, Chengdu 610065

2 Institute of Ecology and Key Laboratory for Earth Surface Processes of the Ministry of Education, College of Urban and Environmental Sciences, Peking University, Beijing 100871

\section{ABSTRACT}

Aims: The genome size between species, especially in angiosperms, can be extremely diverse. Here, we compiled genome size data for 11,215 angiosperm species from 2,226 genera and 245 families to explore the relationships between four functional traits (i.e. seed mass, maximum plant height, leaf nitrogen and phosphorus concentrations) with genome size in angiosperms from different life forms (i.e. annual herbs, perennial herbs, and woody plants).

Method: We used the 1C-value of DNA content as a measurement for genome size. Genome sizes were obtained from the latest version of Kew Plant DNA C-values Database and Genome Size in Asteraceae Database (GSAD). We also complemented our taxon sampling with data from the literature over the past 10 years. We obtained life form and functional trait from Flora of China, Flora of North America and the Seed Information Database (SID). We used the most recent updated time-calibrated phylogeny published by Smith and Brown in 2018, and pruned it to the 6,612 species from our species list. We used two indices (i.e. Blomberg's $K$ and Pagel's $\lambda$ ) to test for the prescence of a phylogenetic signal for the evolution of angiosperm genome size. We performed a standardized major axes (SMA) Model II and focused on the relationships between genome size and the four functional traits. We also conducted a principal components analysis (PCA) to explore trade-offs between functional traits and genome size in angiosperms

收稿日期: 2020-12-05; 接受日期: 2021-02-03

基金项目: 国家自然科学基金(31770566)和国家重点研发计划(2017YFC0505203)

* 通讯作者 Author for correspondence. E-mail: xiaotingxu@pku.edu.cn 
with different life forms.

Results: The genome size for most angiosperms was small and few species had large genomes. The median value of angiosperm genome size was $1.58 \mathrm{pg}$ with perennial herbs having the largest median genome size ( $2.5 \mathrm{pg})$, followed by annual herbs $(1.55 \mathrm{pg})$, and then woody species $(1.14 \mathrm{pg})$. Variation of the genome size was greatest in perennial herbs distributed over a wider range than woody species and then annual herbs. Tests for phylogenetic signals with genome size indicated that evolution was non-random. The value for Blomberg's $K$ was $0.031(P<0.001)$ and the value for Pagel's $\lambda$ was $0.943(P<0.001$. There was also a significant difference between functional traits and genome size among the three different life forms. Our results from the standardized major axes regression found that there was a significant relationship between seed mass with genome size in herbs but not woody plants. However, the relationship of maximum plant height was significant with genome size in woody plants but not herbs. There were no significant correlations between leaf nitrogen or phosphorus concentration with genome size except for leaf nitrogen concentration in woody plants. When looking at the relationship between four functional traits with genome size, we fund a negative correlation between seed mass and maximum plant height with genome size, and saw no significant correlation with leaf nitrogen or phosphorus concentration which is consistent with the SMA results.

Conclusion: Our study highlights that the correlation between functional traits and genome size vary between herbaceous and woody species and suggests that trade-offs between genome size, life forms and functional traits might play an essential role in ecological adaptation and evolution of angiosperms.

Key words: genome size; life forms; leaf nitrogen concentrations; leaf phosphorus concentrations; plant functional traits; seed mass; plant height

基因组大小(genome size)是物种内一套完整单 倍体DNA含量(DNA 1C值)的总和(Greilhuber et al, 2005; 陈建军和王瑛, 2009), 可用重量单位皮克 (picogram, pg)表示, 也可用核苷酸碱基对的数量 (million base pair, Mb)表示, 1 pg约等于 $978 \mathrm{Mb}$ 长度 的碱基对。基因组大小在物种(特别是被子植物)之 间存在巨大的差异(Soltis et al, 2003; Pellicer \& Leitch, 2020)。目前已知的被子植物基因组最小的物 种是螺旋狸藻 (Genlisea tuberosa), 仅 $0.07 \mathrm{pg}$, 而基 因组最大的物种是多年生草本植物重楼百合(Paris japonica), 其基因组高达152.2 pg (Pellicer \& Leitch, 2020)。丰富的基因组大小多样性可能对被子植物的 性状演化、环境适应、物种多样化等过程有着重要 影响(倪丽萍和郭水良, 2005; 郭水良等, 2008, 2015; Knight \& Beaulieu, 2008)。

早期基于分子或细胞水平的研究发现, 植物基 因组大小与细胞分裂持续的时间、细胞大小、植物 叶片气孔密度等存在显著相关性(Baetcke et al, 1967; Bennett, 1972, 1973; Edwards \& Endrizzi, 1975), 这种基因组大小与细胞水平特征的关系可 能会导致物种表型上的差异 (Rees et al, 1996; Hessen et al, 2010; Hodgson et al, 2010; Malerba et al, 2020)。也有研究表明, 基因组大小与细胞大小在植 物、动物等不同类群的不同组织细胞中呈正相关关 系。基于此, 可以推测基因组大的物种可能具有较
大细胞体积的子叶、胚乳等(Bennett，1972，1973), 因此种子重量与基因组大小间可能也存在显著的 正相关关系(Beaulieu et al, 2007)。然而, Krahulcová 等(2017)对无患子科七叶树属(Aesculus) 8个物种的 研究发现, 种子重量与基因组大小呈负相关关系。

Knight 和 Beaulieu (2008) 对被子植物 48 目 139 科 1,222 个物种的研究发现, 基因组大的物种只能发 育出较重的种子, 但基因组小的物种不仅可以发育 出较轻的种子, 也可以发育出较重的种子。同时, 基因组大小与种子重量的关系在不同的属中差异 极大, 既有显著正相关和显著负相关, 也有相关关 系不显著的情况(Knight \& Beaulieu, 2008)。此外, Bennett (1972, 1973) 对24种草本植物的研究发现, 基因组大小随着细胞分裂持续时间的增加而增大, 因而分裂速度越快的物种其基因组越小。而细胞分 裂速度越快, 物种生长速率越快, 则植株高度越高, 因此可以推测植株高度与基因组大小可能呈负相 关关系。Knight等(2005)对324个被子植物物种基因 组大小的研究发现, 最大植株高度与基因组大小存 在显著负相关关系, 且物种植株高度与基因组大小 的负相关关系随着基因组的增大而增强(Knight et $\mathrm{al}, 2005$ )。值得注意的是, 在基因组相对较小的物种 中, 植株高度存在较大变异, 即最矮和最高的物种 都出现在基因组小的物种中。然而, 这些研究的结 果都是基于少量物种, 发现的最大植株高度和种子 
重量与基因组大小的关系在被子植物中是否普遍 存在, 仍然有着极大的不确定性。

氮和磷是生物体内DNA、RNA和蛋白质的重要 组成成分, 在促进植株的光合作用和碳水化合物合 成中起着重要的作用, 是植物生长所必需的营养元 素(Vitousek \& Howarth, 1991; Frink et al, 1999)。然 而, 由于自然生态系统长期处在不同氮、磷元素限 制的状态, 如果植物减少氮和磷元素在DNA中的分 配, 则可以增加RNA和蛋白质中的氮、磷含量, 以 便快速完成基因表达和蛋白质的合成, 提高植物的 生长速率。因此, 在氮、磷元素限制的环境中, 植 物体内的氮和磷元素含量较低, 基因组小的物种更 具有竞争优势, 这就是生长速率与基因组大小关系 的营养元素限制假说 (growth rate-genome sizenutrient limitation hypothesis) (Hessen et al, 2010)。根 据该假说, 植物体内的氮、磷元素含量越高, 受到 的氮、磷元素限制越小, 基因组越大; 反之则基因 组越小。Kang等(2015)对中国喀斯特地区报春苣苔 属(Primulina) 99个物种的研究发现, 该属物种的叶 片氮含量与基因组大小显著正相关, 但叶片磷含量 与其关系并不显著。氮、磷元素添加实验发现, 小 基因组物种在氮、磷元素受限的群落中更占优势, 而大基因组物种在氮、磷元素充足的群落中占据优 势(Guignard et al, 2016)。这些研究表明氮、磷元素 限制可能限制了群落中一些具有特定基因组大小 的物种的共存, 因此有必要考虑叶片氮、磷含量对 基因组大小的影响。

对不同生活型植物基因组大小的比较研究发 现, 草本植物比木本植物的表皮细胞面积更大, 保 卫细胞更长, 气孔密度更低, 基因组更大(Beaulieu et al, 2008)。此外, 草本植物的基因组大小变异范围 超过2,000倍, 而木本植物仅为 240 倍(Ohri, 2005; 陈建军和王瑛, 2010)。然而, 草本植物与木本植物 在细胞水平上及生活史周期的差异是否会影响功 能性状与基因组大小之间的关系, 还有待进一步研 究。因此, 本研究广泛收集了11,215个被子植物物 种的基因组大小数据, 其中有明确生活型记录的物 种包括922种一年生草本植物、5,266种两年生及多 年生草本植物和 3,101 种木本植物, 结合最大植株 高度、种子重量和叶片氮、磷含量的数据, 拟探讨 以下问题: (1)被子植物的基因组大小在不同生活型 物种间的差异; (2)验证植株高度、叶片氮含量和叶
片磷含量是否与基因组大小呈负相关关系, 种子重 量是否与基因组大小呈正相关关系的假设; (3)比较 上述不同生活型的被子植物功能性状与基因组大 小间权衡关系的差异。

\section{数据来源与方法}

\section{1 基因组大小数据来源}

本研究将基因组大小定义为物种的DNA 1C值 (Greilhuber et al, 2005)。DNA 1C 值数据来源于最新 版的植物 DNA C 值数据库 (Plant DNA C-values Database, release 7.1, https://cvalues. science.kew.org/) 和菊科植物基因组大小数据库 (Genome Size in Asteraceae Database, GSAD, release 3.0, https://www. asteraceaegenome-size.com/)。植物DNA C值数据库 是目前最完整的植物基因组大小数据库, 其中包含 了10,770种(包含种下等级)被子植物的基因组大小 数据。菊科植物基因组大小数据库包含了 1,555 种菊 科植物(包含种下等级)的基因组大小数据。此外, 我 们还查阅了2008-2019年发表的482篇文献，补充了 新报道的被子植物基因组大小的数据(附录1)。

本研究使用植物名称校对数据库(Taxonomic NamesResolution Service, TNRS, http://tnrs.iplant-col laborative.org/)对所有来源的物种名称进行了校对, 并将亚种和变种数据整合到种的阶元。当一个物种 有多条基因组大小数据时, 我们用这些数据的中位 数来表示该物种的基因组大小。

\section{2 生活型和功能性状数据来源}

本研究使用的物种生活型和最大植株高度数据 主要来源于中国植物志(http://www.iplant.cn/frps)、 Flora of China (http://www.efloras.org/)和 Flora of North America (FNA, http://beta.floranorthamerica.or $\mathrm{g} /$ )。此外, 木本和草本生活型的划分还参考了Zanne 等(2014)整理的全球被子植物生活型数据库及 Engemann等(2016)整理的新大陆植物生活型数据 库; 草本一年生与多年生物种 (含两年生物种)的划 分依据为植物DNA C值数据库; 最大植株高度数据 同时参考了Wang等(2019)公开的数据库。物种的种 子重量数据来自邱园种子信息数据库(Seed Information Database, SID, release 7.1, http://data.kew.org /sid/)。叶片氮、磷含量数据来自于全球陆生植物叶 片氮、磷含量数据库(Tian et al, 2019), 该数据库共 收集了 3,227 种被子植物叶片氮、磷元素的 11,354 条 
记录, 本研究使用物种内多条记录的中位数表示对 应物种的叶片元素含量。

\section{3 统计分析}

\subsection{1 不同生活型物种基因组大小的比较}

为比较不同生活型的物种基因组大小的差异, 本研究对不同类型的物种分别绘制了频率直方图 并计算了基因组大小分布的偏度(skewness)。因植 物基因组大小不服从正态分布, 本研究首先采用 Kruskal-Wallis检验比较不同生活型物种的基因组 大小之间是否存在显著性差异, 然后采用Dunn多 重检验比较任意两组生活型物种之间基因组大小 的差异, 并采用Benjamini和Hochberg (1995)提出的 hochberg方法对 $P$ 值进行校正(adjusted- $P$ ), 以减少 多重检验中产生I型错误的概率。基因组大小分布的 偏度、基因组大小的频率分布图和皮尔森相关性系 数分别使用 $\mathrm{R}$ 软件中的mean函数、hist函数和corr函 数进行计算。使用vioplot程序包(Adler \& Kelly, 2020)中的vioplot函数绘制小提琴图。Kruskal-Wallis 检验和Dunn多重检验使用FSA程序包完成(Ogle et $\mathrm{al}, 2020$ )。本文所有统计分析均在 R 3.5.3 (R Development Core Team, 2019)中完成。

\subsection{2 系统发育树与系统发育信号}

为计算被子植物基因组大小的系统发育信号, 本文参考最新版本的被子植物系统发育框架(Smith \& Brown, 2018)构建了一棵含有6,612个物种(木本 物种 1,773 个, 草本物种 4,818 个)的系统发育树, 数 据量覆盖 249 科 1,738 属。采用 Blomberg' $K$ (Blomberg et al, 2003)和Pagel's $\lambda$ (Pagel, 1999)检验 基因组大小的演化是否存在系统发育信号。系统发 育树的提取利用phytools程序包中的keep.tip函数完 成(Revell, 2012), Blomberg' $K$ 和Pagel's $\lambda$ 的计算利 用 $\mathrm{R}$ 软件 picante程序包的 phylosignal 函数完成 (Kembel et al, 2010)。

\subsection{3 植物功能性状与基因组大小的关系}

本研究采用标准化主轴法(standardized major axes, SMA, Model II regression)估计不同功能性状 和基因组大小之间的关系。标准化主轴法是针对线 性回归中因变量和自变量不确定、均存在测量误差 的情况下使用的一种方法, 该方法能够找到两个变 量的最优线性拟合关系(Warton \& Weber, 2002)。为 比较不同生活型物种功能性状与基因组大小的关 系, 本研究分别对所有物种、木本植物、一年生草
本和多年生草本植物的功能性状与基因组大小之 间的关系进行了SMA分析，并比较了SMA模型在 斜率上的差异(Warton et al, 2006)。SMA分析采用R 软件 smatr程序包中的 sma函数完成(Warton et al, 2012)。为分析被子植物 4 种功能性状与基因组大小 的权衡关系, 本研究采用主成分分析 (principal components analysis, PCA)方法分析了来自51个科 的 215 个物种( 95 个木本物种, 120 个草本物种)的 4 种 功能性状与基因组大小之间的权衡关系。主成分分 析采用 $\mathrm{R}$ 软件中的prcomp函数完成。

\section{结果}

\section{1 不同生活型被子植物基因组大小}

本研究共收集来自于被子植物 245科 2,226属 11,215种的基因组大小数据, 其中草本植物 8,048 种, 木本植物仅 3,101 种, 有66种生活型不清楚。草本植 物中明确为一年生的有922种, 明确为多年生的有 5,266 种，有 1,860 种的生活型未见明确记录。各类生 活型被子植物的基因组大小以小基因组为主，大基 因组物种较少，整体明显右偏分布(图1a、b、c)。被 子植物基因组大小的中值为 $1.58 \mathrm{pg}$, 其中多年生草 本植物最大, 为 $2.5 \mathrm{pg}$; 其次是一年生草本植物, 为 $1.55 \mathrm{pg}$; 木本植物最小，仅1.14 pg。Kruskal-Wallis 检验表明不同生活型之间的基因组大小存在极显 著差异 $(P<0.001)$, Dunn多重检验结果表明多年生 草本植物基因组大小极显著大于一年生草本植物 (adjusted- $P<0.001$ ), 而一年生草本植物的基因组 大小极显著大于木本植物(图1d)。就基因组大小变 异范围而言, 多年生草本植物最大, 其次是木本植 物，一年生草本植物最小(表1)。

基于6,612种被子植物物种系统发育树计算得 到的基因组大小演化的谱系发育信号Blomberg's $K$ 为0.031 $(P<0.001)$, Pagel's $\lambda$ 为0.943 $(P<0.001)$, 表明被子植物基因组大小具有极显著的系统发育 信号，即被子植物基因组大小是非随机进化的。 Blomberg's $K<1$, 说明与随机进化过程相比, 亲缘 关系越近的物种其基因组大小越相似。

\section{2 种子重量与基因组大小的关系}

基于3,909个被子植物物种的基因组大小和种 子重量数据的SMA分析发现，种子重量与基因组大 小的相关性在不同生活型间存在显著差异 
表1 被子植物不同生活型物种的基因组大小及功能性状信息

Table 1 Quantitative information of genome size and functional traits among angiosperms with different life forms

\begin{tabular}{|c|c|c|c|c|c|c|c|}
\hline & $\begin{array}{l}\text { 生活型 } \\
\text { Life form }\end{array}$ & $\begin{array}{l}\text { 科样本量 } \\
\text { Family number }\end{array}$ & $\begin{array}{l}\text { 属样本量 } \\
\text { Genus number }\end{array}$ & $\begin{array}{l}\text { 物种样本量 } \\
\text { Species number }\end{array}$ & $\begin{array}{l}\text { 均值 } \\
\text { Mean }\end{array}$ & $\begin{array}{l}\text { 最小值 } \\
\text { Min. }\end{array}$ & $\begin{array}{l}\text { 最大值 } \\
\text { Max. }\end{array}$ \\
\hline \multirow{5}{*}{$\begin{array}{l}\text { 基因组大小 } \\
\text { Genome size (pg) }\end{array}$} & 所有物种 All species & 245 & 2,226 & 11,215 & 4.74 & 0.07 & 152.2 \\
\hline & 木本植物 Woody species & 155 & 486 & 3,101 & 2.33 & 0.17 & 83.60 \\
\hline & 草本植物 Herbs & 151 & 1,531 & 8,048 & 5.76 & 0.07 & 152.20 \\
\hline & 一年生草本植物 Annual herbs & 46 & 299 & 922 & 2.94 & 0.12 & 23.62 \\
\hline & 多年生草本植物 Perennial herbs & 136 & 1,101 & 5,266 & 6.64 & 0.07 & 152.20 \\
\hline \multirow{5}{*}{$\begin{array}{l}\text { 种子重量 } \\
\text { Seed mass (g) }\end{array}$} & 所有物种 All species & 189 & 1,243 & 3,909 & 68.37 & 0.001 & 25,406 \\
\hline & 木本植物 Woody species & 118 & 442 & 1,061 & 216.76 & 0.009 & 25,406 \\
\hline & 草本植物 Herbs & 114 & 866 & 2,840 & 12.52 & 0.001 & $9,238.6$ \\
\hline & 一年生草本植物 Annual herbs & 46 & 250 & 597 & 13.77 & 0.003 & 393.5 \\
\hline & 多年生草本植物 Perennial herbs & 107 & 728 & 2,225 & 12.19 & 0.001 & $9,238.6$ \\
\hline \multirow{5}{*}{$\begin{array}{l}\text { 最大植株高度 } \\
\text { Maximum plant } \\
\text { height (m) }\end{array}$} & 所有物种 All species & 142 & 733 & 1,737 & 3.55 & 0.001 & 60 \\
\hline & 木本植物 Woody species & 94 & 277 & 554 & 9.34 & 0.15 & 60 \\
\hline & 草本植物 Herbs & 79 & 494 & 1,183 & 0.84 & 0.001 & 25 \\
\hline & 一年生草本植物 Annual herbs & 35 & 145 & 268 & 0.77 & 0.01 & 8 \\
\hline & 多年生草本植物 Perennial herbs & 75 & 410 & 915 & 0.87 & 0.001 & 25 \\
\hline \multirow{5}{*}{$\begin{array}{l}\text { 叶片氮含量 } \\
\text { Leaf nitrogen } \\
\text { concentration (mg/g) }\end{array}$} & 所有物种 All species & 74 & 256 & 437 & 22.02 & 3.69 & 66.80 \\
\hline & 木本植物 Woody species & 51 & 118 & 209 & 20.85 & 4.93 & 66.80 \\
\hline & 草本植物 Herbs & 33 & 141 & 227 & 23.10 & 3.69 & 53.70 \\
\hline & 一年生草本植物 Annual herbs & 9 & 36 & 42 & 25.76 & 10.11 & 53.70 \\
\hline & 多年生草本植物 Perennial herbs & 31 & 116 & 185 & 22.49 & 3.69 & 49.11 \\
\hline \multirow{5}{*}{$\begin{array}{l}\text { 叶片磷含量 } \\
\text { Leaf phosphorus } \\
\text { concentration (mg/g) }\end{array}$} & 所有物种 All species & 74 & 256 & 437 & 1.83 & 0.21 & 7.30 \\
\hline & 木本植物 Woody species & 51 & 118 & 209 & 1.59 & 0.21 & 5.20 \\
\hline & 草本植物 Herbs & 33 & 141 & 227 & 2.05 & 0.32 & 7.30 \\
\hline & 一年生草本植物 Annual herbs & 9 & 36 & 42 & 2.51 & 0.80 & 5.09 \\
\hline & 多年生草本植物 Perennial herbs & 31 & 116 & 185 & 1.94 & 0.32 & 7.30 \\
\hline
\end{tabular}
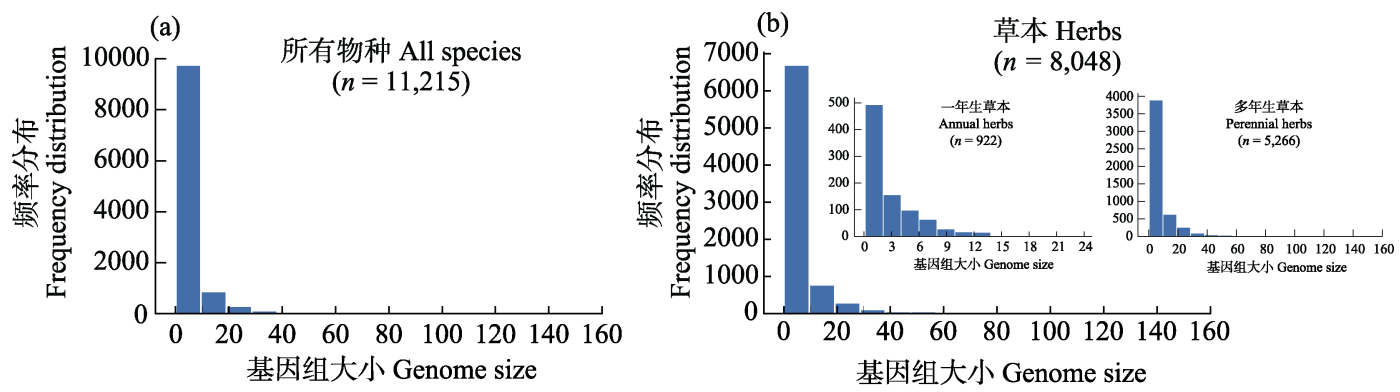

(c)

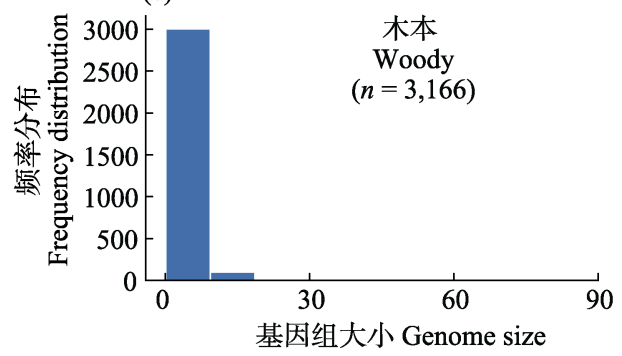

(d)

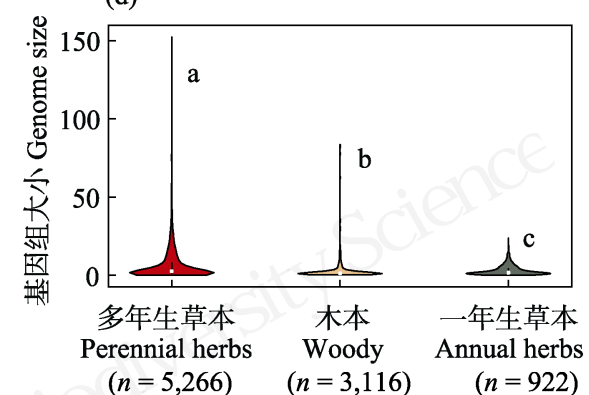

图1 被子植物基因组大小(pg)在不同生活型间的频率分布。(a)所有被子植物; (b)草本植物; (c)木本植物; (d)基因组大小的分 布(小提琴图), 其中a、b、c表示不同生活型物种的基因组大小之间存在显著性差异(adjusted-P $<0.01)$, 圆形点表示各生活型 物种的基因组大小的中值。

Fig. 1 Distribution of genome size (pg) for angiosperms with different life forms. (a) All angiosperms; (b) Herbaceous species; (c) Woody species; (d) Violin plot of genome size, in which letter a, b and c indicate significant differences in genome size for species with different life form, and circular dots represent the median values of genome size. 
(adjusted- $P<0.001$ )。整体上, 所有被子植物的种子 重量与基因组大小之间存在显著的正相关关系 $(n=$ $3,909$, slope $=1.962, P<0.05)$, 即被子植物的种子 越大, 基因组也越大(图2a)。划分生活型后, 一年生 与多年生草本物种的种子重量与基因组大小之间 均存在极显著正相关关系(一年生: $n=597$, slope $=$ $2.231, P<0.001$; 多年生: $n=2,225$, slope $=1.559, P$ $<0.001$ ), 与全部被子植物物种的趋势一致(图 $2 \mathrm{~b}$ 、

c)。然而, 木本植物种子重量与基因组大小之间的 关系不显著 $(n=1,061$, slope $=-2.774, P>0.1)$ (图 2d)。

\section{3 植株高度与基因组大小的关系}

SMA分析结果表明, 最大植株高度与基因组 大小的相关性在不同生活型中存在极显著差异 (adjusted- $P<0.001$ )。整体上, 所有被子植物物种植 株高度与基因组大小的关系存在极显著的负相关 关系 $(n=1,737$, slope $=-1.246, P<0.001)$ (图3a)。对

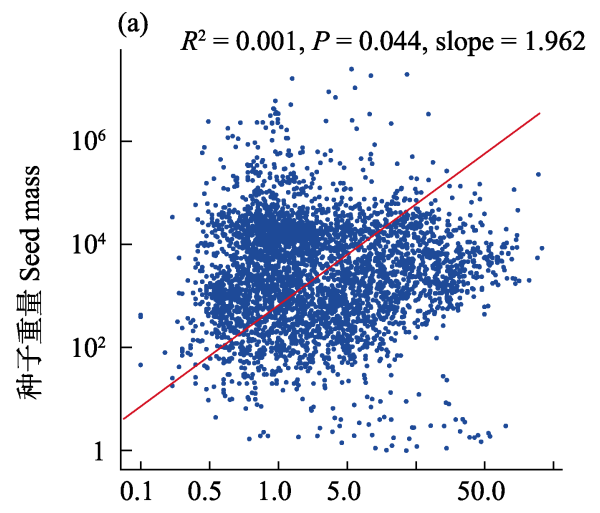

(c) $R^{2}=0.028, P<0.001$, slope $=1.559$

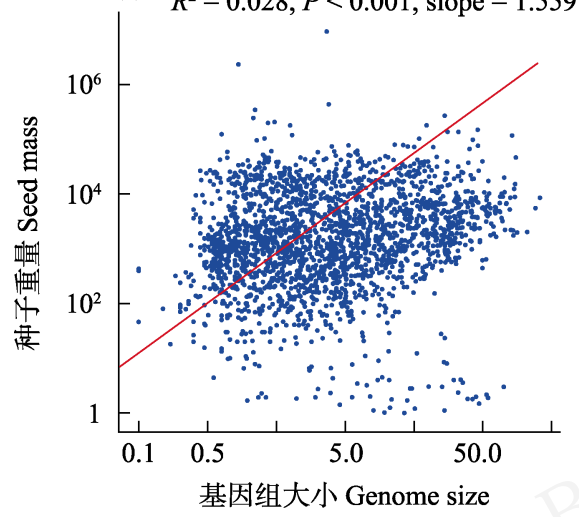

比不同生活型被子植物发现, 只有木本植物的最大 植株高度与基因组大小之间极显著负相关 $(n=554$, slope $=-1.526, P<0.001)$, 而草本植物的最大植株 高度与基因组大小无显著相关关系(一年生: $n=268$, slope $=0.872, P>0.1$; 多年生: $n=915$, slope $=$ $-0.749, P>0.1$ ) (图3b、c)。所有被子植物最大植株 高度与基因组大小的相关性主要受木本植物类群 影响(图3)。

\section{4 叶片氮、磷含量与基因组大小的关系}

SMA分析结果表明, 叶片氮含量与基因组大 小的相关性在不同生活型中存在极显著差异 (adjusted- $P<0.001$ )。对比不同生活型被子植物发现, 叶片氮含量与基因组大小在木本植物中呈显著负 相关关系 $(n=209$, slope $=-0.487, P<0.05)$, 但在一 年生草本植物和多年生草本植物及所有被子植物 物种中均无显著相关关系(所有物种: $n=437$, slope $=-0.371, P>0.1 ;$ 一年生: $n=42$, slope $=-0.41, P$
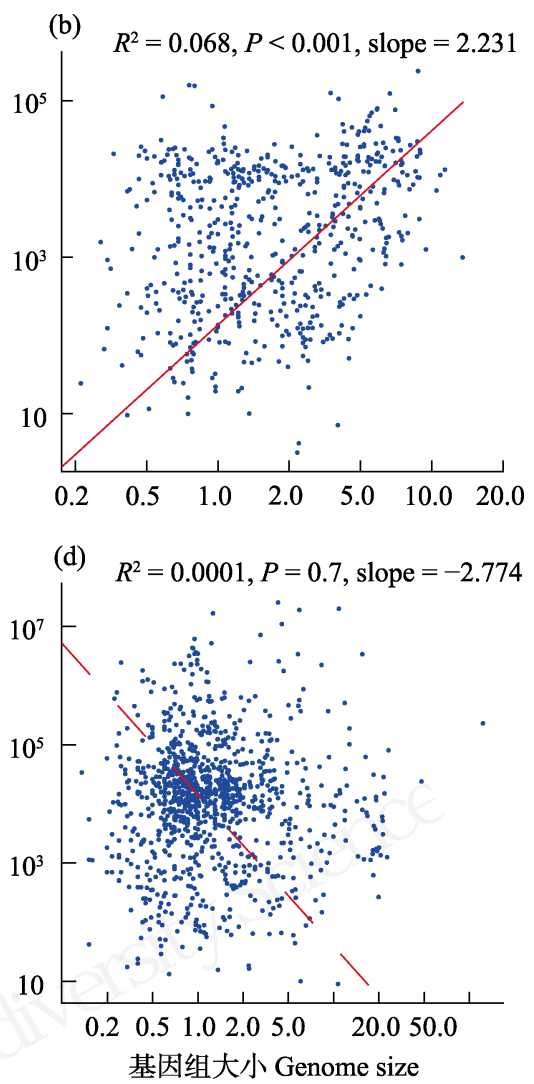

图2 不同生活型被子植物种子重量(经lg转换)与基因组大小(经lg转换)的相关性。(a)所有被子植物; (b)一年生草本植物; (c) 多年生草本植物; (d)木本植物。

Fig. 2 Correlations between seed mass (lg scale) and genome size (lg scale) for all angiosperms (a), annual herbs (b), perennial herbs (c), and (d) woody species. 

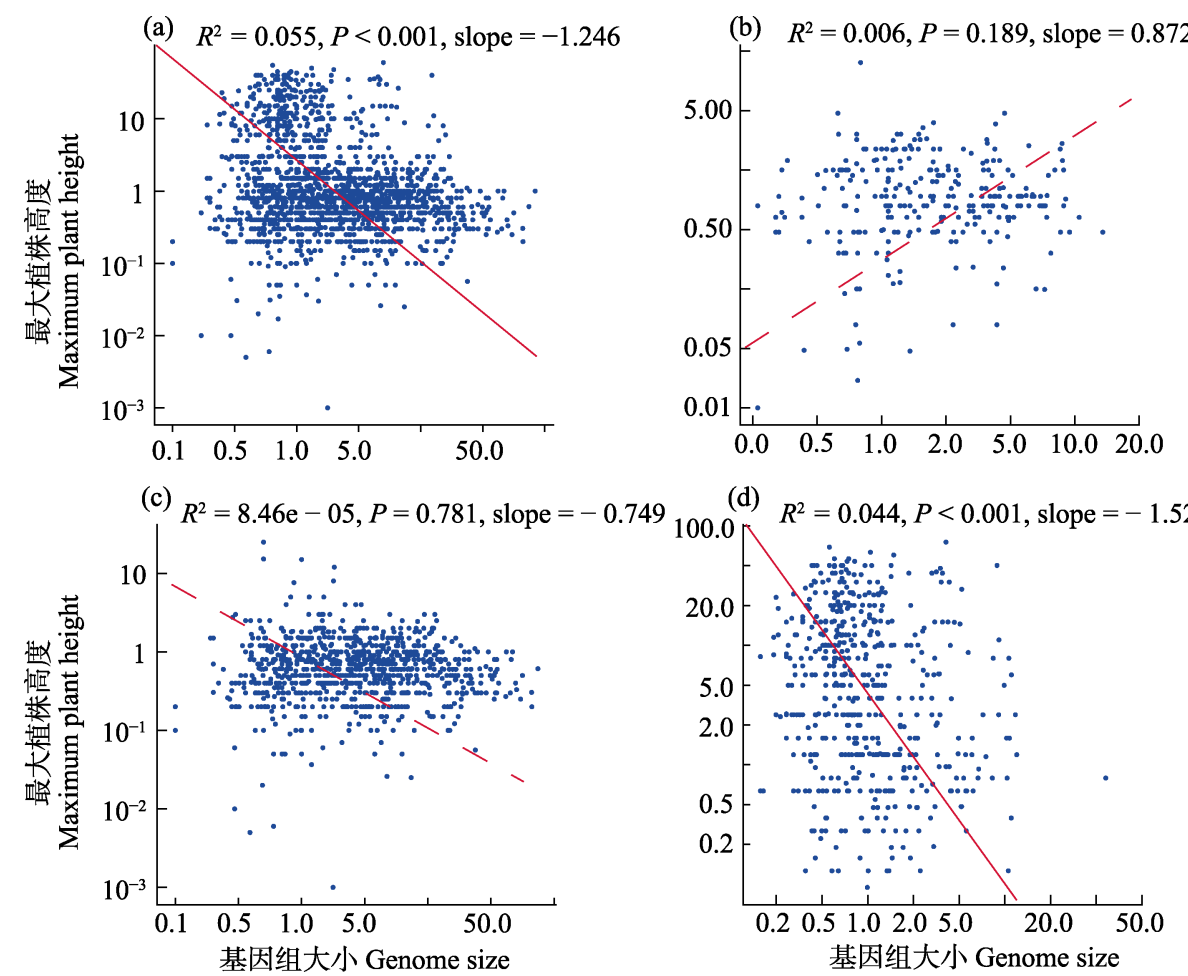

(d) $R^{2}=0.044, P<0.001$, slope $=-1.526$

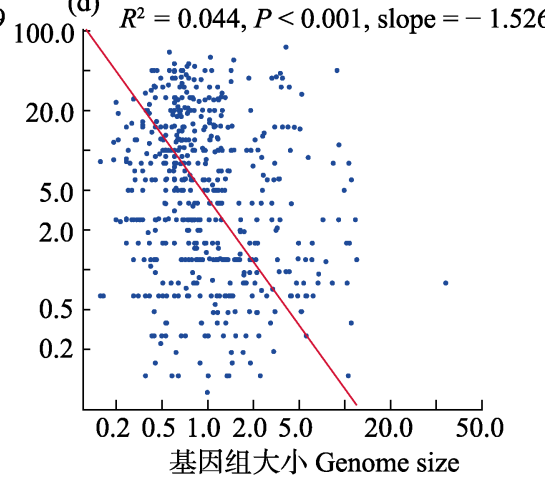

图3 不同生活型被子植物最大植株高度(经lg转换)与基因组大小(经lg转换)的相关性。(a)所有被子植物; (b)一年生草本植物; (c)多年生草本植物; (d)木本植物。

Fig. 3 Correlations between maximum plant height (lg scale) and genome size (lg scale)of different life form angiosperms. (a) All angiosperms; (b) Annual herbs; (c) Perennial herbs; (d) Woody species.
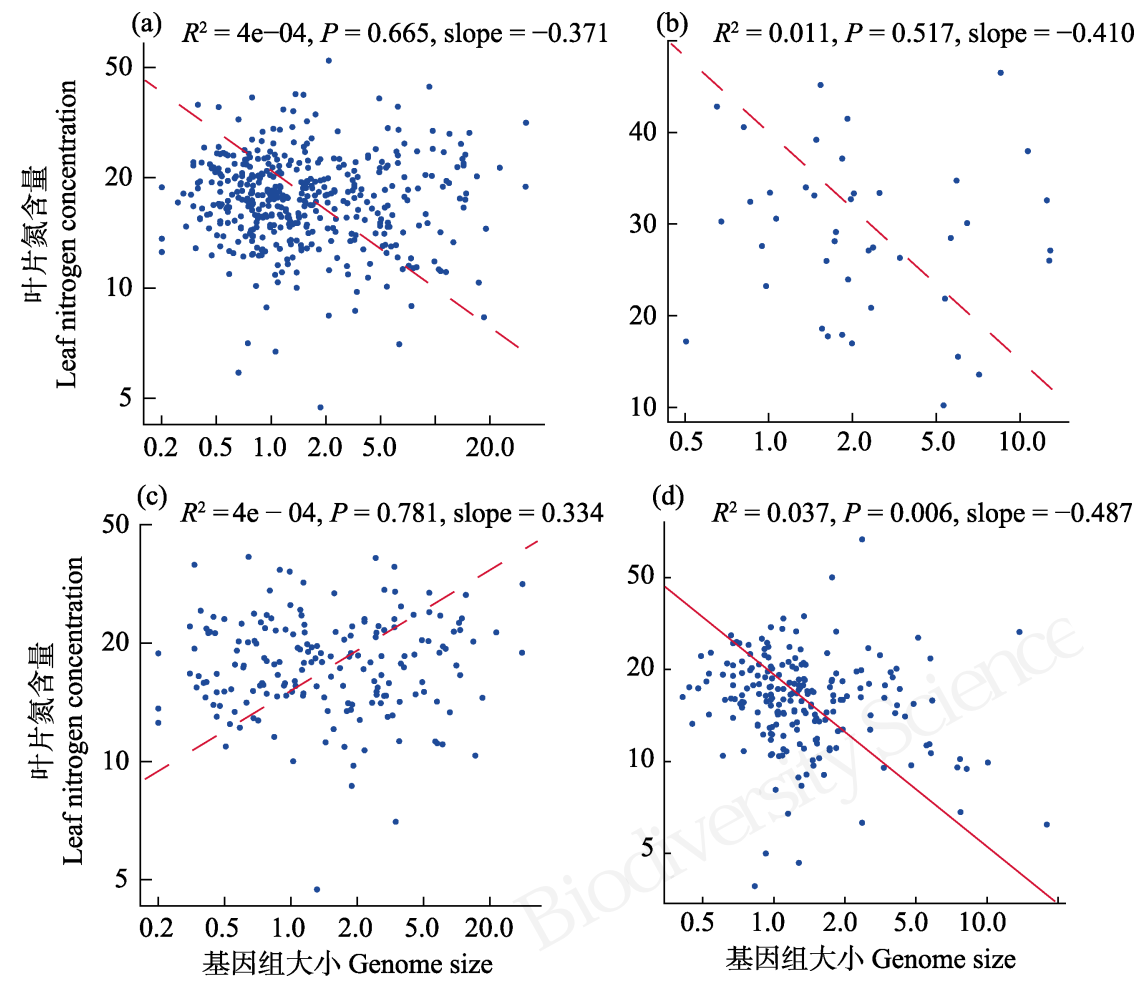

图4 不同生活型被子植物叶片氮含量(经lg转换)与基因组大小(经lg转换)的相关性。(a)所有被子植物; (b)一年生草本植物; (c) 多年生草本植物; (d)木本植物。

Fig. 4 Correlations between leaf nitrogen concentration (lg scale)and genome size (lg scale) of different life form angiosperms. (a) All angiosperms; (b) Annual herbs; (c) Perennial herbs; (d) Woody species. 


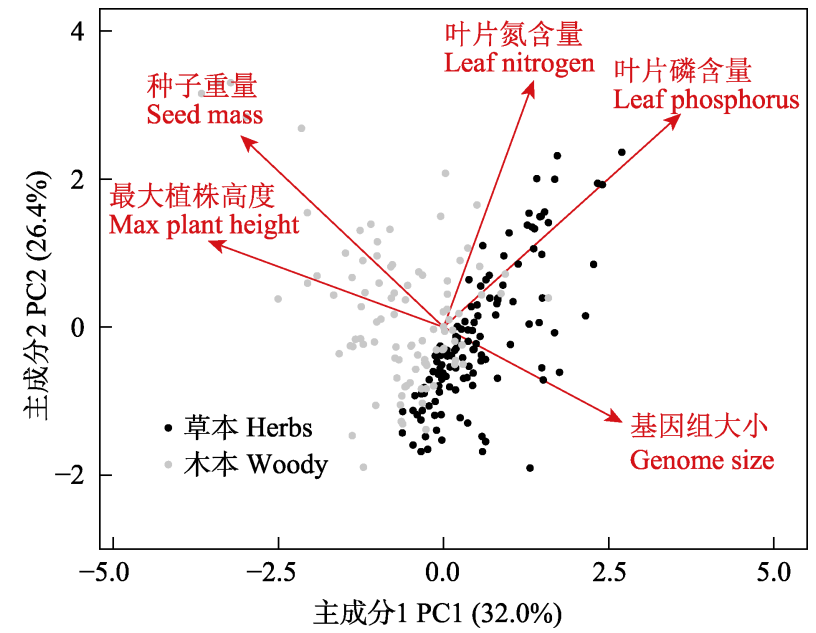

图5 不同生活型被子植物功能性状与基因组大小的权衡

Fig. 5 Trade-offs between functional traits and genome size among angiosperms with different life forms

$>0.1$; 多年生: $n=185$, slope $=0.334, P>0.1$ ) (图 4a、b、c)。在所有被子植物及不同生活型物种中, 叶 片磷含量与基因组大小均无显著相关关系(附录2)。

\section{5 功能性状与基因组大小的权衡关系}

来自 51 科的 95 种木本植物和 120 种草本植物的 4种功能性状与基因组大小的权衡关系表明(图5), 种子重量及最大植株高度与基因组大小呈负相关 关系, 而叶片氮、磷含量与基因组大小无显著相关 性。木本物种普遍最大植株高度高且种子重量大, 但基因组大小较小; 草本物种则与之相反。

\section{3 讨论}

\section{1 被子植物种子重量与基因组大小的关系}

本研究发现被子植物的种子重量与基因组大 小间的显著正相关关系仅在一年生草本和多年生 草本植物中存在, 而在木本植物中未检测到。本结 果部分支持了前人对种子重量与基因组大小呈正 相关关系的推测(Moles et al, 2005; Beaulieu et al, 2007)。草本植物和木本植物种子重量与基因组大小 关系的差异可能与不同生活型物种基因组大小与 细胞大小之间的关系不同有关。Edwards和Endrizzi 早在1975年就基于基因组大小与细胞大小之间的 正相关关系推测出种子重量与基因组大小呈正相 关关系(Edwards \& Endrizzi, 1975)。Beaulieu等(2008) 对41种草本植物、26种灌木和34种乔木的比较研究 发现, 乔木和灌木物种的叶表皮细胞大小及其变异 范围均显著小于草本植物, 乔木的叶表皮细胞的长
度及面积与基因组大小的关系不显著。由此推测木 本植物细胞大小的稳定性可能影响了其基因组大 小的稳定性，从而导致种子重量与基因组大小之间 没有显著的相关关系。然而, Beaulieu等(2008)的研 究中涉及到的物种数目有限, 关于木本植物叶表皮 细胞大小与基因组大小的关系还需要更大范围的 取样才能验证。因此, 本研究建议同时对多种植物 的基因组大小、叶表皮细胞大小和种子重量进行测 量, 以更好地验证细胞大小和种子重量与基因组大 小的关系。

本研究与以往研究结果的差异可能有以下几 个原因。(1)本研究使用的数据量更多, 更能从总体 上揭示被子植物种子重量与基因组大小的关系。如 Beaulieu等(2007)也研究了被子植物种子大小与基 因组大小的关系, 但该研究只使用了 1,087 种被子 植物。本研究共包括被子植物3,909种, 物种数目接 近Beaulieu等(2007)的3倍(表1)。(2)以往的研究通常 数据量有限, 有的只关注单一的生活型, 有的不区 分生活型。如Leishman (1999)研究了英国分布的16 种草地物种, Maranon和Grubb (1993)研究了地中海 地区19种一年生草本植物, Knight和Ackerly (2002) 研究了 148 种加利福尼亚地区分布的物种, Thompson (1990)研究了131种英国分布的被子植 物。除了Leishman (1999)外, 以往大部分对草本植 物的研究均发现, 种子大小与基因组大小呈正相关 关系。尽管有关木本被子植物种子大小与基因组大 小关系的研究相对较少, 但研究发现被子植物种子 大小与基因组大小的关系可能受到木本植物、一年 生或多年生草本植物物种取样偏差的影响。(3)种子 重量受多种因素控制, 例如光照、土壤营养元素供 给、繁殖策略等都可能影响不同物种间的种子重量 的差异。使用偏回归分析, 可在控制其他潜在变量 后研究基因组大小对种子重量的影响, 这有助于揭 示基因组大小对种子重量的独立影响。

\section{2 被子植物最大植株高度与基因组大小的关系}

草本植物和木本植物的最大植株高度存在显 著差异(表1), 这种差异可能是物种最大植株高度与 基因组大小的三角形关系产生的原因之一。本研究 基于1,737种被子植物的研究结果与Knight等(2005) 基于324种植物的结果相似：物种最大高度与基因 组大小呈显著的负相关关系, 但基因组小的物种最 
大高度变异较大, 既有最矮的物种也有最高的物 种。当划分生活型后, 只有木本植物的植株高度与 基因组大小呈现显著的负相关关系, 并未出现 Knight等(2005)发现的三角形关系。但是, 草本植物 最大植株高度与基因组大小没有显著的相关关系。 这可能是由于高大的树木可获得更为丰富的光资 源, 能够维持植株更大的生物量, 有助于物种扩展 其生态位(niche)。因此, 木本植物植株高度与基因 组大小的显著负相关关系可能暗示着木本植物中 基因组小的物种更有潜力发育得较高大因而更占 优势。

\section{3 被子植物叶片氮、磷含量与基因组大小的关系} 本研究发现, 仅木本植物叶片中的氮含量与基 因组大小呈负相关关系, 而草本植物的叶片氮含量 与基因组大小并没有显著关系，这部分支持了 Hessen等(2010)提出的生长速率与基因组大小关系 的营养元素限制假说。本研究的结果可能受以下因 素的影响: (1)取样数据量过小。一年生草本植物的 物种数量仅 42 个, 多年生草本物种仅 185 个 (表 1 ), 可能不足以反映一年生草本植物和多年生草本植 物基因组大小与叶片元素含量的关系。(2)本研究使 用的叶片氮、磷含量的数据主要以群落水平研究为 主, 这会导致对物种(特别是分布范围较大的物种) 取样不全, 叶片平均氮和磷含量的估计出现误差。

(3)不同物种对氮、磷元素重吸收的量可能更能反映 植物受到氮、磷元素限制的状态(Han et al, 2013; Yuan \& Chen, 2015; 陈婵等, 2019; He et al, 2020)。 未来研究中可通过测量叶片氮、磷元素的重吸收效 率, 分析物种基因组大小与叶片氮、磷元素重吸收 效率的关系以更好地验证生长速率与基因组大小 关系的营养元素限制假说。(4)本研究仅有437个被 子植物物种同时具有基因组大小与叶片氮、磷含量 的数据, 取样量整体偏小, 也容易发生非随机取样, 这些因素可能导致叶片氮、磷含量与基因组大小关 系的不确定性。因此, 对被子植物叶片氮、磷含量 与基因组大小的关系及在不同生活型物种之间的 差异仍有待进一步验证。

综上, 本研究发现被子植物功能性状与基因组 大小的关系在不同生活型之间存在显著性差异。木 本植物最大植株高度和叶片氮含量与基因组大小 均呈显著的负相关关系, 种子重量与基因组大小关 系不显著。一年生和多年生草本植物的种子重量与
基因组大小呈显著的正相关关系, 最大植株高度和 叶片氮、磷含量与基因组大小的关系不显著。本研 究中涉及的一年生草本植物物种总数仅 922 种, 同 时具有最大高度、种子重量和叶片氮、磷含量的物 种数目更少, 因此一年生草本植物物种的功能性状 与基因组大小之间的关系还有待进一步的验证。

与前期研究结果一致(Puttick et al, 2015), 本研 究也发现基因组大小的演化有明显的系统发育信 号。Beaulieu等(2008)对基因组大小与种子重量的谱 系独立性分析 (phylogenetic independent contrast, PIC)发现, 被子植物基因组大小的变异与种子重量 的变异存在显著正相关, 表明基因组大小与种子重 量在系统发育上可能存在一定的相关性。虽然本研 究中涉及的功能性状较多, 但在系统发育树上覆盖 的物种较少, 因此本研究中未考虑系统发育关系的 影响。因此, 在未来的研究中, 增加基因组大小和 相关性状在系统进化树上的采样数量, 结合谱系独 立性分析或者系统发育广义最小二乘法 (phylogenetic generalized least squares, PGLS)的分 析方法, 能够更准确地研究植物功能性状与基因组 大小的关系以及性状与基因组大小关系的演化。另 外, 系统发育保守性和环境因素如何共同影响基因 组大小以及性状与基因组大小之间的权衡关系也 有待进一步研究。

\section{ORCID}

邵晨 (iD) https://orcid.org/0000-0003-4680-789X 李耀琪 (iD https://orcid.org/0000-0001-6540-395X 王志恒 (1) https://orcid.org/0000-0003-0808-7780 席祯翔 (1) https://orcid.org/0000-0002-2851-5474 徐晓婷 (D) https://orcid.org/0000-0001-8126-614X

\section{参考文献}

Adler D, Kelly T (2020) vioplot. R package version 0.3.5. https://github.com/TomKellyGenetics/vioplot/. (accessed on 2020-11-25)

Baetcke KP, Sparrow AH, Nauman CH, Schwemmer SS (1967) The relationship of DNA content to nuclear and chromosome volumes and to radiosensitivity (LD50). Proceedings of the National Academy of Sciences, USA, 58, 533-540.

Beaulieu JM, Moles AT, Leitch IJ, Bennett MD, Dickie JB, Knight CA (2007) Correlated evolution of genome size and seed mass. New Phytologist, 173, 422-437.

Beaulieu JM, Leitch IJ, Patel S, Pendharkar A, Knight CA (2008) Genome size is a strong predictor of cell size and 
stomatal density in angiosperms. New Phytologist, 179, 975-986.

Benjamini Y, Hochberg Y (1995) Controlling the false discovery rate: A practical and powerful approach to multiple testing. Journal of the Royal Statistical Society Series B: Statistical Methodology, 57, 289-300.

Bennett MD (1972) Nuclear DNA content and minimum generation time in herbaceous plants. Proceedings of the Royal Society of London Series B: Biological Sciences, 181, 109-135.

Bennett MD (1973) Nuclear characters in plants. Brookhaven Symposia in Biology, 25, 344-366.

Blomberg SP, Garland T, Ives AR (2003) Testing for phylogenetic signal in comparative data: Behavioral traits are more labile. Evolution, 57, 717-745.

Chen C, Zhang SJ, Li LD, Liu ZD, Chen JL, Gu X, Wang LF, Fang $X$ (2019) Carbon, nitrogen and phosphorus stoichiometry in leaf, litter and soil at different vegetation restoration stages in the mid-subtropical region of China. Chinese Journal of Plant Ecology, 43, 658-671. (in Chinese with English abstract) [陈婵, 张仕吉, 李雷达, 刘兆丹, 陈 金磊, 喜翔, 王留芳, 方晰 (2019) 中亚热带植被恢复阶 段植物叶片、调落物、土壤碳氮磷化学计量特征. 植物生 态学报, 43, 658-671.]

Chen JJ, Wang Y (2009) Recent progress in plant genome size evolution. Hereditas, 31, 464-470. (in Chinese with English abstract) [陈建军, 王瑛 (2009) 植物基因组大小进化的 研究进展. 遗传, 31, 464-470.]

Edwards GA, Endrizzi JE (1975) Cell size, nuclear size and DNA content relationships in Gossypium. Canadian Journal of Genetics and Cytology, 17, 181-186.

Engemann K, Sandel B, Boyle B, Enquist BJ, Jørgensen PM, Kattge J, McGill BJ, Morueta-Holme N, Peet RK, Spencer NJ, Violle C, Wiser SK, Svenning JC (2016) A plant growth form dataset for the New World. Ecology, 97, 3243-3243.

Frink CR, Waggoner PE, Ausubel JH (1999) Nitrogen fertilizer, retrospect and prospect. Proceedings of the National Academy of Sciences, USA, 96, 1175-1180.

Greilhuber J, Doležel J, Lysák MA, Bennett MD (2005) The origin, evolution and proposed stabilization of the terms 'Genome size' and 'Evalue' to describe nuclear DNA contents. Annals of Botany, 95, 255-260.

Guignard MS, Nichols RA, Knell RJ, MacDonald A, Romila CA, Trimmer M, Leitch IJ, Leitch AR (2016) Genome size and ploidy influence angiosperm species' biomass under nitrogen and phosphorus limitation. New Phytologist, 210, 1195-1206.

Guo SL, Chen GQ, Mao LH (2008) Relationship between DNA $\mathrm{C}$-value and invasiveness in 539 angiosperm species in China. Acta Ecologica Sinica, 28, 3698-3705. (in Chinese with English abstract) [郭水良, 陈国奇, 毛俐慧 (2008) DNA C-值与被子植物入侵性关系的数据统计分析以中国境内有分布的 539 种被子植物为例. 生态学报, 28, 3698-3705.]
Guo SL, Yu J, Li DD, Zhou P, Fang Q, Yin LP (2015) DNA $\mathrm{C}$-values of 138 herbaceous species and their biological significance. Acta Ecologica Sinica, 35, 6516-6529. (in Chinese with English abstract) [郭水良, 于晶, 李丹丹, 周 平, 方其, 印丽萍 (2015) 长三角及邻近地区138种草本 植物DNA C-值测定及其生物学意义. 生态学报, 35, 6516-6529.]

Han WX, Tang LY, Chen YH, Fang JY (2013) Relationship between the relative limitation and resorption efficiency of nitrogen vs. phosphorus in woody plants. PLoS ONE, 8, e83366.

He MS, Yan ZB, Cui XQ, Gong YM, Li KH, Han WX (2020) Scaling the leaf nutrient resorption efficiency: Nitrogen vs phosphorus in global plants. Science of the Total Environment, 729, 138920.

Hessen DO, Jeyasingh PD, Neiman M, Weider LJ (2010) Genome streamlining and the elemental costs of growth. Trends in Ecology \& Evolution, 25, 75-80.

Hodgson JG, Sharafi M, Jalili A, Díaz S, Montserrat-Martí G, Palmer C, Cerabolini B, Pierce S, Hamzehee B, Asri Y, Jamzad Z, Wilson P, Raven JA, Band SR, Basconcelo S, Bogard A, Carter G, Charles M, Castro-Díez P, Cornelissen JHC, Funes G, Jones G, Khoshnevis M, Pérez-Harguindeguy N, Pérez-Rontomé MC, Shirvany FA, Vendramini F, Yazdani S, Abbas-Azimi R, Boustani S, Dehghan M, Guerrero-Campo J, Hynd A, Kowsary E, Kazemi-Saeed F, Siavash B, Villar-Salvador P, Craigie R, Naqinezhad A, Romo-Díez A, de Torres Espuny L, Simmons E (2010) Stomatal vs. genome size in angiosperms: The somatic tail wagging the genomic dog? Annals of Botany, 105, 573-584.

Kang M, Wang J, Huang HW (2015) Nitrogen limitation as a driver of genome size evolution in a group of karst plants. Scientific Reports, 5, 11636.

Kembel SW, Cowan PD, Helmus MR, Cornwell WK, Morlon H, Ackerly DD, Blomberg SP, Webb CO (2010) Picante: R tools for integrating phylogenies and ecology. Bioinformatics, 26, 1463-1464.

Knight CA, Ackerly DD (2002) Variation in nuclear DNA content across environmental gradients: A quantile regression analysis. Ecology Letters, 5, 66-76

Knight CA, Molinari NA, Petrov DA (2005) The large genome constraint hypothesis: Evolution, ecology and phenotype. Annals of Botany, 95, 177-190.

Knight CA, Beaulieu JM (2008) Genome size scaling through phenotype space. Annals of Botany, 101, 759-766.

Krahulcová A, Trávníček P, Krahulec F, Rejmánek M (2017) Small genomes and large seeds: Chromosome numbers, genome size and seed mass in diploid Aesculus species (Sapindaceae). Annals of Botany, 119, 957-964.

Leishman MR (1999) How well do plant traits correlate with establishment ability? Evidence from a study of 16 calcareous grassland species. New Phytologist, 141, 487-496. 
Maranon T, Grubb PJ (1993) Physiological basis and ecological significance of the seed size and relative growth rate relationship in Mediterranean annuals. Functional Ecology, 7, 591-599.

Malerba ME, Ghedini G, Marshall DJ (2020) Genome size affects fitness in the eukaryotic alga Dunaliella tertiolecta. Current Biology, 30, 3450-3456.

Moles AT, Ackerly DD, Webb CO, Tweddle JC, Dickie JB, Pitman AJ, Westoby M (2005) Factors that shape seed mass evolution. Proceedings of the National Academy of Sciences, USA, 102, 10540-10544.

Ni LP, Guo SL (2005) Review on relationship between invasiveness of plants and their DNA C-value. Acta Ecologica Sinica, 25, 2372-2381. (in Chinese with English abstract) [倪丽萍, 郭水良 (2005) 论DNA C-值与植物入 侵性的关系. 生态学报, 25, 2372-2381.]

Ohri D (2005) Climate and growth form, the consequences for genome size in plants. Plant Biology, 7, 449-458.

Ogle DH, Wheeler P, Dinno A (2020) FSA, Fisheries Stock Analysis. R package version 0.8.30.9000. https://github.com /droglenc/FSA/. (accessed on 2020-11-25)

Pagel M (1999) Inferring the historical patterns of biological evolution. Nature, 401, 877-884.

Pellicer J, Leitch IJ (2020) The Plant DNA C-values database (release 7.1): An updated online repository of plant genome size data for comparative studies. New Phytologist, 226, 301-305.

Puttick MN, Clark J, Donoghue PCJ (2015) Size is not everything: Rates of genome size evolution, not C-value, correlate with speciation in angiosperms. Proceedings of the Royal Society B: Biological Sciences, 282, 20152289.

R Development Core Team (2019) R: A Language and Environment for Statistical Computing. https://www.R-pro ject.org/. (accessed on 2019-01-01)

Rees H, Cameron FM, Hazarika MH, Jones GH (1966) Nuclear variation between diploid angiosperms. Nature, 211, 828-830.

Revell LJ (2012) phytools: An R package for phylogenetic comparative biology (and other things). Methods in Ecology and Evolution, 3, 217-223.

Smith SA, Brown JW (2018) Constructing a broadly inclusive seed plant phylogeny. American Journal of Botany, 105,
302-314.

Soltis DE, Soltis PS, Bennett MD, Leitch IJ (2003) Evolution of genome size in the angiosperms. American Journal of Botany, 90, 1596-1603.

Thompson K (1990) Genome size, seed size and germination temperature in herbaceous angiosperms. Evolutionary Trends in Plants, 4, 113-116.

Tian D, Kattge J, Chen YH, Han WX, Luo YK, He JS, Hu HF, Tang ZY, Ma SH, Yan ZB, Lin QH, Schmid B, Fang JY (2019) A global database of paired leaf nitrogen and phosphorus concentrations of terrestrial plants. Ecology, 100, e02812.

Vitousek PM, Howarth RW (1991) Nitrogen limitation on land and in the sea: How can it occur? Biogeochemistry, 13, 87-115.

Wang ZH, Li YQ, Su XY, Tao SL, Feng X, Wang QG, Xu XT, Liu YP, Michaletz ST, Shrestha N, Larjavaara1 M, Enquist BJ (2019) Patterns and ecological determinants of woody plant height in eastern Eurasia and its relation to primary productivity. Journal of Plant Ecology, 12, 791-803.

Warton DI, Weber NC (2002) Common slope tests for bivariate errors-in-variables models. Biometrical Journal, 44, 161-174.

Warton DI, Wright IJ, Falster DS, Westoby M (2006) Bivariate line-fitting methods for allometry. Biological Reviews, 81, 259-291.

Warton DI, Duursma RA, Falster DS, Taskinen S (2012) smatr 3: An $\mathrm{R}$ package for estimation and inference about allometric lines. Methods in Ecology and Evolution, 3, 257-259.

Yuan ZY, Chen HYH (2015) Negative effects of fertilization on plant nutrient resorption. Ecology, 96, 373-380.

Zanne AE, Tank DC, Cornwell WK, Eastman JM, Smith SA, Fitzjohn RG, McGlinn DJ, O’Meara BC, Moles AT, Reich PB, Royer DL, Soltis DE, Stevens PF, Westoby M, Wright IJ, Aarssen L, Bertin RI, Calaminus A, Govaerts R, Hemmings F, Leishman MR, Oleksyn J, Soltis PS, Swenson NG, Warman L, Beaulieu JM (2014) Three keys to the radiation of angiosperms into freezing environments. Nature, 506, 89-92.

(责任编委: 葛学军 责任编辑: 黄祥忠)

\section{附录 Supplementary Material}

\section{附录1 基因组大小数据收集参考文献}

Appendix 1 References of genome size data

https://www.biodiversity-science.net/fileup/PDF/2020450-1.pdf

附录2 不同生活型被子植物叶片磷含量与基因组大小的相关性

Appendix 2 Correlations between genome size and leaf phosphorus concentration of different life form angiosperms https://www.biodiversity-science.net/fileup/PDF/2020450-2.pdf 
邵晨, 李耀琪, 罗奥, 王志恒, 席祯翔, 刘建全, 徐晓婷 (2021) 不同生活型被子植物功能性状与基因组大小的

关系. 生物多样性, 29, 575-585. http://www.biodiversity-science.net/CN/10.17520/biods.2020450

附录 1 基因组大小数据收集参考文献

Appendix 1 References of genome size data

Bai CK, Alverson WS, Follansbee A, Waller DM (2012) New reports of nuclear DNA content for 407 vascular plant taxa from the United States. Annals of Botany, 110, 1623-1629.

Baziz K, Benamara-Bellagha M, Pustahija F, Brown SC, Siljak-Yakovlev S, Khalfallah N (2014) First karyotype analysis, physical rDNA mapping, and genome size assessment in 4 North African Astragalus taxa (Fabaceae). Turkish Journal of Botany, 38, 1248-1258.

Bose B, Kumaria S, Choudhury H, Tandon P (2017) Insights into nuclear DNA content, hydrogen peroxide and antioxidative enzyme activities during transverse thin cell layer organogenesis and ex vitro acclimatization of Malaxis wallichii, a threatened medicinal orchid. Physiology and Molecular Biology of Plants, 23, 955-968.

Brem MC, Coulleri JP, Volponi CR, Volponi CR, Ferrucci MS (2018) Genome size, karyotypic features and pollen size in Argentinian species of Spergula (Caryophyllaceae). Boletín de la Sociedad Argentina de Botánica, 53, 255-266.

Cao Z, Deng ZN, McLaughlin M (2014) Interspecific genome size and chromosome number variation shed new light on species classification and evolution in Caladium. Journal of the American Society for Horticultural Science, 139, 449-459.

Carović-Stanko K, Liber Z, Besendorfer V, Javornik B, Bohanec B, Kolak I, Satovic Z (2010) Genetic relations among basil taxa (Ocimum L.) based on molecular markers, nuclear DNA content, and chromosome number. Plant Systematics and Evolution, 285, 13-22.

Carta A, Moretti M, Nardi FD, Siljak-Yakovlev S, Peruzzi L (2015) Seed morphology and genome size in two Tuscan Crocus (Iridaceae) endemics: C. etruscus and C. ilvensis. Caryologia, 68, 97-100.

Castro S, Romeiras MM, Castro M, Duarte MC, Loureiro J (2013) Hidden diversity in wild Beta taxa from Portugal: Insights from genome size and ploidy level estimations using flow cytometry. Plant Science, 207, 72-78.

Chae WB, Hong SJ, Gifford JM, Rayburn AL, Sacks EJ, Juvik JA (2014) Plant morphology, genome size, and SSR markers differentiate five distinct taxonomic groups among accessions in the genus Miscanthus. Global Change Biology Bioenergy, 6, 646-660.

Chen JJ, Liu XL, Zhu LY, Wang Y (2013) Nuclear genome size estimation and karyotype analysis of Lycium species (Solanaceae). Scientia Horticulturae, 151, 46-50.

Chen SC, Cannon CH, Kua CS, Liu JJ, Galbraith DW (2014) Genome size variation in the Fagaceae and its implications for trees. Tree Genetics and Genomes, 10, 977-988.

Chen WH, Kao YL, Tang CY, Tsai CC, Lin TY (2013) Estimating nuclear DNA content within 50 species of the genus Phalaenopsis Blume (Orchidaceae). Scientia Horticulturae, 161, 70-75.

Chen ZY, Xiong ZJ, Pan XY, Shen SQ, Geng YP, Xu CY, Chen JK, Zhang WJ (2015) Variation of genome size and the ribosomal DNA ITS region of Alternanthera philoxeroides (Amaranthaceae) in Argentina, the USA, and China. Journal of Systematics and Evolution, 53, 82-87.

Chiarini FE, Santiñaque FF, Urdampilleta JD, Las Peñas ML (2014) Genome size and karyotype diversity in Solanum sect. Acanthophora (Solanaceae). Plant Systematics and Evolution, 300, 113-125.

Chumová Z, Krejčíková J, Mandáková T, Suda J, Trávníček P (2015) Evolutionary and taxonomic implications of variation in nuclear genome size: Lesson from the grass genus Anthoxanthum (Poaceae). PLoS ONE, 10, e0133748.

Collevatti RG, Dornelas MC (2016) Clues to the evolution of genome size and chromosome number in Tabebuia alliance (Bignoniaceae). Plant Systematics and Evolution, 302, 601-607.

Coulleri JP, Urdampilleta JD, Ferrucci MS (2014) Genome size evolution in Sapindaceae at subfamily level: A case study of independence in relation to karyological and palynological traits. Botanical Journal of the Linnean Society, 174, 589-600.

Du WW, Wang XN, Duan Q, Jia WJ, Ma LL, Cui GF, Wang JH (2018) Genome size comparison in 34 Begonia L. species. Journal of Plant Genetic Resources, 19, 370-376. (in Chinese with English abstract) [杜文文, 王祥宁, 段 青, 贾文杰, 马璐琳, 崔光芬, 王继华 (2018) 34 种秋海棠基因组大小比较与分析. 植物遗传资源学报, 19, 370-376.]

Dudáš M, Fabianová J, Mártonfiová L, Mártonfi P (2019) Petasites kablikianus (Asteraceae) in the Slovak Carpathians: Distribution, chromosome number and genome size. Botanica Serbica, 43, 23-30.

Elansary M, Winkelmann T (2014) Preparing interspecific hybridization in the genus Lobelia - Nuclear DNA contents, pollen handling, and localization of crossing barriers. European Journal of Horticultural Science, 79, 290-299.

Fan HJ, Chai Z, Yin FD, Huang HY, Chen LL (2019) Estimation of genome size of Forsythia suspensa (Thunb.) vahl by flow cytometry. Lishizhen Medicine and Materia Medica Research, 30, 758-760. (in Chinese with English 
邵晨, 李耀琪, 罗奥, 王志恒, 席祯翔, 刘建全, 徐晓婷 (2021) 不同生活型被子植物功能性状与基因组大小的

关系. 生物多样性, 29, 575-585. http://www.biodiversity-science.net/CN/10.17520/biods.2020450

abstract) [樊慧杰, 柴智, 殷福栋, 黄浩楹, 陈乐乐 (2019) 连尧基因组大小的流式细胞仪测定. 时珍国医国 药, 30, 758-760.]

Frajman B, Rešetnik I, Weiss-Schneeweiss H, Ehrendorfer F, Schönswetter P (2015) Cytotype diversity and genome size variation in Knautia (Caprifoliaceae, Dipsacoideae). BMC Evolutionary Biology, 15, 1-18.

Frajman B, Záveská E, Gamisch A, Moser T, The STEPPE Consortium, Schönswetter P (2019) Integrating phylogenomics, phylogenetics, morphometrics, relative genome size and ecological niche modelling disentangles the diversification of Eurasian Euphorbia seguieriana s. l. (Euphorbiaceae). Molecular Phylogenetics and Evolution, 134, 238-252.

Fridley JD, Craddock A (2015) Contrasting growth phenology of native and invasive forest shrubs mediated by genome size. New Phytologist, 207, 659-668.

Garcia S, Hidalgo O, Jakovljević I, Siljak-Yakovlev S, Vigo J, Garnatje T, Vallès J (2013) New data on genome size in 128 Asteraceae species and subspecies, with first assessments for 40 genera, 3 tribes and 2 subfamilies. Plant Biosystems, 147, 1219-1227.

Gouja H, García-Fernández A, Garnatje T, Raïes A, Neffati M (2014) Genome size and phylogenetic relationships between the Tunisian species of the genus Calligonum (Polygonaceae). Turkish Journal of Botany, 38, 13-21.

Gschwend AR, Wai CM, Zee F, Arumuganathan AK, Ming R (2013) Genome size variation among sex types in dioecious and trioecious Caricaceae species. Euphytica, 189, 461-469.

Gomes SSL, Saldanha CW, Neves CS, Trevizani M, Raposo NRB, Notini MM, Oliveira Santos M, Campos JMS, Otoni WC, Viccini LF (2014) Karyotype, genome size, and in vitro chromosome doubling of Pfaffia glomerata (Spreng.) Pedersen. Plant Cell, Tissue and Organ Culture (PCTOC), 118, 45-56.

Gomes SSL, Vidal JD, Neves CS, Zorzatto C, Campacci TVS, Lima AK, Koehler S, Viccini LF (2018) Genome size and climate segregation suggest distinct colonization histories of an orchid species from Neotropical high-elevation rocky complexes. Biological Journal of the Linnean Society, 124, 456-465.

He XX, Zhong Q, Zhong YL, Jie YC (2019) Determination of ramie (Boehmeria nivea) genome size by flow cytometry. Molecular Plant Breeding, 17, 99-103. (in Chinese with English abstract) [何金坌，钟启，钟英丽，揭雨成 (2019) 流式细胞术测定芳麻基因组大小. 分子植物育种, 17, 99-103.]

Hidalgo O, Garcia S, Garnatje T, Mumbrú M, Patterson A, Vigo J, Vallès J (2015) Genome size in aquatic and wetland plants: Fitting with the large genome constraint hypothesis with a few relevant exceptions. Plant Systematics and Evolution, 301, 1927-1936.

Hoang PTN, Schubert V, Meister A, Fuchs J, Schubert I (2019) Variation in genome size, cell and nucleus volume, chromosome number and rDNA loci among duckweeds. Scientific Reports, 9, 3234.

Hoshi Y, Azumatani M, Suyama C, Adamec L (2017) Determination of ploidy level and nuclear DNA content in the Droseraceae by flow cytometry. Cytologia, 82, 321-327.

Huang H, Tong Y, Zhang QJ, Gao LZ (2013) Genome size variation among and within Camellia species by using flow cytometric analysis. PLoS ONE, 8, e64981.

Ilhan E, Ozgur S, Tuna GS, Eren AH, Karahan F, Tuna M, Erayman M (2017) Nuclear DNA content variation among Glycyrrhiza taxons collected from East Mediterranean. Fresenius Environmental Bulletin, 26, 3251-3256.

Jian H, Zhang T, Wang Q, Yan H, Qiu XQ, Zhou N, Li SB, Chen M, Zhang H, Tang KX (2014) Nuclear DNA content and 1CX-value variations in genus Rosa L. Caryologia, 67, 273-280.

Jiang Y, Xu S, Han X (2017) Investigation of nuclear DNA contents of Lycoris species (Amaryllidaceae) with different chromosome number by flow cytometry. Pakistan Journal of Botany, 49, 2197-2200.

Jordan GJ, Carpenter RJ, Koutoulis A, Price A, Brodribb TJ (2015) Environmental adaptation in stomatal size independent of the effects of genome size. New Phytologist, 205, 608-617.

Kang M, Tao JJ, Wang J, Ren C, Qi QW, Xiang QY, Huang HW (2014) Adaptive and nonadaptive genome size evolution in karst endemic flora of China. New Phytologist, 202, 1371-1381.

Kaur N, Datson PM, Murray BG (2012) Genome size and chromosome number in the New Zealand species of Schoenus (Cyperaceae). Botanical Journal of the Linnean Society, 169, 555-564.

Krahulcová A, Trávníček P, Krahulec F, Rejmánek M (2017) Small genomes and large seeds: Chromosome numbers, genome size and seed mass in diploid Aesculus species (Sapindaceae). Annals of Botany, 119, 957-964.

Koláŕ F, Lučanová M, Vít P, Urfus T, Chrtek J, Fér T, Ehrendorfer F, Suda J (2013) Diversity and endemism in deglaciated areas: Ploidy, relative genome size and niche differentiation in the Galium pusillum complex (Rubiaceae) in Northern and Central Europe. Annals of Botany, 111, 1095-1108.

Koçyiğit M, Tuna M (2016) Taxonomic remarks on the genus Sternbergia L. (Amaryllidaceae) in Turkey based on leaf 
anatomy, karyosystematic analysis and nuclear DNA content. Phytotaxa, 265, 238-250.

Kumar PP, Turner IM, Nagaraja Rao A, Arumuganathan K (2011) Estimation of nuclear DNA content of various bamboo and rattan species. Plant Biotechnology Reports, 5, 317-322.

Lattier JD, Ranney TG, Fantz PR, Avent T (2014) Identification, nomenclature, genome sizes, and ploidy levels of Liriope and Ophiopogon taxa. HortScience, 49, 145-151.

Lee YI, Chung MC, Kuo HC, Wang CN, Lee YC, Lin CY, Jiang H, Yeh CH (2017) The evolution of genome size and distinct distribution patterns of rDNA in Phalaenopsis (Orchidaceae). Botanical Journal of the Linnean Society, 185, 65-80.

Leitch IJ, Kahandawala I, Suda J, Hanson L, Ingrouille MJ, Chase MW, Fay MF (2009) Genome size diversity in orchids: Consequences and evolution. Annals of Botany, 104, 469-481.

Li WW, Liu LQ, Pamier A, Wang YN, Cheng G, Liao K (2019) Identification of chromosomal ploidy and DNA content in Xinjiang Armeniaca vulgaris by flow cytometry. Journal of Agricultural Biotechnology, 27, 542-550. (in Chinese with English abstract) [李雯雯, 刘立强, 帕米尔·艾尼, 王亚楠, 程功, 廖康 (2019) 利用流式细胞术鉴定新疆 野杏染色体倍性 DNA 含量. 农业生物技术学报, 27, 542-550.]

Lin F, Xiao YE, Zhou XY, Tang Y, Gao BH (2018) Estimation of genomic C value of 25 samples of Iris plants by flow cytometry. Acta Agrestia Sinica, 26, 985-990. (in Chinese with English abstract) [林峰, 肖月娥, 周翔宇, 唐颖, 高步红 (2018) 25 份感尾属植物基因组 DNA C 值的流式测定. 草地学报, 26, 985-990.]

Lipnerová I, BurešP, Horová L, Šmarda P (2013) Evolution of genome size in Carex (Cyperaceae) in relation to chromosome number and genomic base composition. Annals of Botany, 111, 79-94.

Lysak MA, Koch MA, Beaulieu JM, Meister A, Leitch IJ (2009) The dynamic ups and downs of genome size evolution in Brassicaceae. Molecular Biology and Evolution, 26, 85-98.

Mandák B, Krak K, Vít P, Pavlíková Z, Lomonosova MN, Habibi F, Wang L, Jellen EN, Douda J (2016) How genome size variation is linked with evolution within Chenopodium sensu lato. Perspectives in Plant Ecology, Evolution and Systematics, 23, 18-32.

Matzk F, Hammer K, Schubert I (2003) Coevolution of apomixis and genome size within the genus Hypericum. Sexual Plant Reproduction, 16, 51-58.

Meiners J, Debener T, Schweizer G, Winkelmann T (2011) Analysis of the taxonomic subdivision within the genus Helleborus by nuclear DNA content and genome-wide DNA markers. Scientia Horticulturae, 128, 38-47.

Mishiba KI, Yamane K, Nakatsuka T, Nakano Y, Yamamura S, Abe J, Kawamura H, Takahata Y, Nishihara M (2009) Genetic relationships in the genus Gentiana based on chloroplast DNA sequence data and nuclear DNA content. Breeding Science, 59, 119-127.

Moja S, Guitton Y, Nicolè F, Legendre L, Pasquier B, Upson T, Jullien F (2016) Genome size and plastid trnK-matK markers give new insights into the evolutionary history of the genus Lavandula L. Plant Biosystems, 150, 12161224.

Müller LLB, Zotz G, Albach DC (2019) Bromeliaceae subfamilies show divergent trends of genome size evolution. Scientific Reports, 9, 1-12.

Nani TF, Mesquita AT, Bustamante FDO, Barbosa S, Barbosa JVC, Davide LC (2015) Variation of karyotype and nuclear DNA content among four species of Plectranthus L’ Héritier, 1788 (Lamiaceae) from Brazil. Comparative Cytogenetics, 9, 549-563.

Ni JJ, He B, Wang WJ, Yu K (2015) Flow cytometric analysis of genome size in Atractylodes lancea. Journal of Chinese Medicinal Materials, 38, 1153-1156. (in Chinese with English abstract) [倪金菁，贺涁，汪文杰，余坤 (2015) 流 式细胞法测定茅苍术基因组大小. 中药材, 38, 1153-1156.]

Ng CH, Lee SL, Tnah LH, Ng KKS, Lee CT, Madon M (2016) Genome size variation and evolution in Dipterocarpaceae. Plant Ecology \& Diversity, 9, 437-446.

Obae SG, West TP (2010) Nuclear DNA content of Hydrastis canadensis L. and genome size stability of in vitro regenerated plantlets. Plant Cell, Tissue and Organ Culture (PCTOC), 102, 259-263.

Omondi EO, Debener T, Linde M, Abukutsa-Onyango M, Dinssa FF, Winkelmann T (2017) Mating biology, nuclear DNA content and genetic diversity in spider plant (Cleome gynandra) germplasm from various African countries. Plant Breeding, 136, 578-589.

Palma-Rojas C, Jara-Seguel P, Von Brand E (2012) Nuclear DNA content in Chilean species of Phycella and Rhodolirium (Amaryllidaceae). Gayana Botanica, 69, 184-185.

Pan YZ, Zhang YC, Gong X, Li FS (2014) Estimation of genome size of four Panax species by flow cytometry. Plant Diversity and Resources, 36, 233-236. (in Chinese with English abstract) [潘跃芝, 张亦弛, 龚洵, 李富生 (2014) 
邵晨, 李耀琪, 罗奥, 王志恒, 席祯翔, 刘建全, 徐晓婷 (2021) 不同生活型被子植物功能性状与基因组大小的

关系. 生物多样性, 29, 575-585. http://www.biodiversity-science.net/CN/10.17520/biods.2020450

4 种人参属植物基因组大小的测定. 植物分类与资源学报, 36, 233 - 236.]

Pang HB, Gao Q, Li YY, Ma CY, Liu HX, Yang CY, Lü RX (2016) Genome size estimation of Bidens bipinnata L. by using flow cytometry. Genomics and Applied Biology, 35, 1800-1804. (in Chinese with English abstract) [逢洪波, 高秋, 李玥荣, 马纯艳, 刘宏金金, 杨成瑶, 吕瑞雪 (2016) 利用流式细胞仪测定鬼针草基因组大小. 基因组 学与应用生物学, 35, 1800-1804.]

Parris JK, Ranney TG, Knap HT, Baird WV (2010) Ploidy levels, relative genome sizes, and base pair composition in Magnolia. Journal of the American Society for Horticultural Science, 135, 533-547.

Pellicer J, Kelly LJ, Magdalena C, Leitch IJ (2013) Insights into the dynamics of genome size and chromosome evolution in the early diverging angiosperm lineage Nymphaeales (water lilies). Genome, 56, 437-449.

Pellicer J, Kelly LJ, Leitch IJ, Zomlefer WB, Fay MF (2014) A universe of dwarfs and giants: Genome size and chromosome evolution in the monocot family Melanthiaceae. New Phytologist, 201, 1484-1497.

Peruzzi L, Nardi FD, Siljak-Yakovlev S (2015) Genome size estimates for nine species of Gagea salisb. (Liliaceae) from the Mediterranean region. Caryologia, 68, 347-350.

Poggio L, Realini MF, Fourastié MF, García AM, González GE (2014) Genome downsizing and karyotype constancy in diploid and polyploid congeners: A model of genome size variation. AoB Plants, 6, plu029.

Prančl J, Kaplan Z, Trávníček P, Jarolímová V (2014) Genome size as a key to evolutionary complex aquatic plants: Polyploidy and hybridization in Callitriche (Plantaginaceae). PLoS ONE, 9, e105997.

Razafinarivo NJ, Rakotomalala JJ, Brown SC, Bourge M, Hamon S, Kochko A, Poncet V, Dubreuil-Tranchant C, Couturon E, Guyot R, Hamon P (2012) Geographical gradients in the genome size variation of wild coffee trees (Coffea) native to Africa and Indian Ocean Islands. Tree Genetics and Genomes, 8, 1345-1358.

Róis AS, Castro S, Loureiro J, Sádio F, Rhazi L, Guara-Requena M, Caperta AD (2018) Genome sizes and phylogenetic relationships suggest recent divergence of closely related species of the Limonium vulgare complex (Plumbaginaceae). Plant Systematics and Evolution, 304, 955-967.

Rothleutner JJ, Friddle MW, Contreras RN (2016) Ploidy levels, relative genome sizes, and base pair composition in Cotoneaster. Journal of the American Society for Horticultural Science, 141, 457-466.

Sadhu A, Bhadra S, Bandyopadhyay M (2016) Novel nuclei isolation buffer for flow cytometric genome size estimation of Zingiberaceae: A comparison with common isolation buffers. Annals of Botany, 118, 1057-1070.

Sakhanokho HF, Islam-Faridi N (2013) Nuclear DNA content, base composition, and cytogenetic characterization of Christia obcordata. Journal of the American Society for Horticultural Science, 138, 205-209.

Sakhanokho HF, Islam-Faridi MN, Rajasekaran K, Pounders CT (2018) Diversity in nuclear DNA content and ploidy level of Hedychium species and hybrids. Journal of Crop Improvement, 32, 431-439.

Sakhanokho HF, Rinehart TA, Stringer SJ, Islam-Faridi MN, Poundersc CT (2018) Variation in nuclear DNA content and chromosome numbers in blueberry. Scientia Horticulturae, 233, 108-113.

Sakhanokho HF, Babiker EM, Smith BJ, Drackett PR (2019) High-frequency somatic embryogenesis, nuclear DNA estimation of milkweed species (Asclepias latifolia, A. speciosa, and A. subverticillata), and genome size stability of regenerants. Plant Cell, Tissue and Organ Culture (PCTOC), 137, 149-156.

Samoluk SS, Chalup L, Robledo G, Seijo JG (2015) Genome sizes in diploid and allopolyploid Arachis L. species (section Arachis). Genetic Resources and Crop Evolution, 62, 747-763.

Schneider JV, Paule J, Gitaí J, Dressler S, Gusmão CLS, Benko-Iseppon AM (2015) Divergent genome sizes reflect the infrafamilial subdivision of the Neotropical woody Marcgraviaceae. Botanical Journal of the Linnean Society, 177, $1-14$.

Shearer K, Ranney TG (2013) Ploidy levels and relative genome sizes of species, hybrids, and cultivars of dogwood (Cornus spp.). HortScience, 48, 825-830.

Šlenker M, Zozomová-Lihová J, Mandáková T, Kudoh H, Zhao YP, Soejima A, Yahara T, Skokanová K, Španiel S, Marhold K (2018) Morphology and genome size of the widespread weed Cardamine occulta: How it differs from cleistogamic C. kokaiensis and other closely related taxa in Europe and Asia. Botanical Journal of the Linnean Society, 187, 456-482.

Štubňová E, Hodálová I, Kučera J, Mártonfiová L, Svitok M, Slovák M (2017) Karyological patterns in the European endemic genus Soldanella L.: Absolute genome size variation uncorrelated with cytotype chromosome numbers. American Journal of Botany, 104, 1241-1253.

Suda J, Kyncl T, Jarolímová V (2005) Genome size variation in Macaronesian angiosperms: Forty percent of the Canarian endemic flora completed. Plant Systematics and Evolution, 252, 215-238.

Suda J, Krahulcová A, Trávníček P, Rosenbaumová R, Peckert T, Krahulec F (2007) Genome size variation and species 
relationships in Hieracium sub-genus Pilosella (Asteraceae) as inferred by flow cytometry. Annals of Botany, 100, 1323-1335.

Sun HG, Wei CX, Yang MX, Gao F, Zhou YJ (2019) Estimation of genome sizes of Astragalus membranaceus based on flow cytometry and K-mer analysis. Chinese Traditional and Herbal Drugs, 50, 1448-1452. (in Chinese with English abstract) [孙会改, 韦春香, 杨旻啸, 高飞, 周宜君 (2019) 基于流式细胞术和 K-mer 分析的黄芪基因 组大小估测. 中草药, 50, 1448-1452.]

Tanaka H, Chotekajorn A, Kai S, Ishigaki G, Hashiguchi M, Akashi R (2016) Determination of genome size, chromosome number, and genetic variation using inter-simple sequence repeat markers in Lotus spp. Cytologia, 81, 95-102.

Timbó ALO, Pereira RC, Souza Sobrinho F, Davide LC (2014) Nuclear DNA content and chromosome number in Brachiaria spp. genotypes. Revista Ciência Agronômica, 45, 62-67.

Trávníček P, Ponert J, Urfus T, Jersáková J, Vrána J, Hřibová E, Doležel J, Suda J (2015) Challenges of flow-cytometric estimation of nuclear genome size in orchids, a plant group with both whole-genome and progressively partial endoreplication. Cytometry, 87, 958-966.

Tyagi A, Sandhya, Sharma P, Saxena S, Sharma R, Amitha Mithra SV, Solanke AU, Singh NK, Sharma TR, Gaikwad $\mathrm{K}$ (2019) The genome size of clusterbean (Cyamopsis tetragonoloba) is significantly smaller compared to its wild relatives as estimated by flow cytometry. Gene, 707, 205-211.

Veleba A, Bureš P, Adamec L, Šmarda P, Lipnerová I, Horová L (2014) Genome size and genomic GC content evolution in the miniature genome-sized family Lentibulariaceae. New Phytologist, 203, 22-28.

Veleba A, Šmarda P, Zedek F, Horová L, Šmerda J, Bureš P (2017) Evolution of genome size and genomic GC content in carnivorous holokinetics (Droseraceae). Annals of Botany, 119, 409-416.

Veselý P, Bureš P, Šmarda P, Pavlíček T (2012) Genome size and DNA base composition of geophytes: The mirror of phenology and ecology? Annals of Botany, 109, 65-75.

Vižintin L, Kosovel V, Feoli Chiapella L (2012) Genetic characterization of Genista sericea Wulfen (Cytiseae Fabaceae) as revealed by nuclear DNA content and ITS nrDNA region analysis. Acta Botanica Croatica, 71, 195205.

Voronkova M, Banaev E, Tomoshevich M, Ak-Lama T (2018) Variation of nuclear DNA content in seeds of Nitraria schoberi L. BIO Web of Conferences, 11, 00046.

Wang CY, Zhang K, Liang F, Cui B, Ma RL (2015) Estimation of genome size of Cymbidium faberi Rolfe. Northern Horticulture, 11, 86-90. (in Chinese with English abstract) [汪琛颖, 张坤, 梁芳, 崔波, 马润林 (2015) 萬兰 (Cymbidium faberi Rolfe) 基因组大小测定. 北方园艺, 11, 86-90.]

Wang GY, Yang YP (2016) The effects of fresh and rapid desiccated tissue on estimates of Ophiopogoneae genome size. Plant Diversity, 38, 190-193.

Wang GY, Meng Y, Yang YP (2017) Genome size variation among and within Ophiopogoneae species by flow cytometric analysis. Brazilian Journal of Botany, 40, 529-537.

Wang X, Chen HZ, Li YF, Han R, Chen H (2018) Determination of genome size of Halocnemum strobilaceum. Journal of Biology, 35, 100-102. (in Chinese with English abstract) [王霞, 陈慧泽, 李永峰, 韩榕, 陈惠 (2018) 盐节木 基因组大小的测定. 生物学杂志, 35, 100-102.]

Wang X, Zhou JY, Sun HG, Yu RM, Gao F, Zhou YJ (2018) Genomic survey sequencing and estimation of genome size of Ammopiptanthus mongolicus. Journal of Plant Genetic Resources, 19, 143-149. (in Chinese with English abstract) [王雪, 周佳熠, 孙会改, 禹瑞敏, 高飞, 周宜君 (2018) 新疆沙冬青基因组调查测序与基因组大小 预测. 植物遗传资源学报, 19, 143-149.]

Wang YP, Xiao BY, Xiong WB, Wu SD, Ji AJ, Duan LX (2018) Genome size analysis for Morinda officinalis how using flow cytometry. Traditional Chinese Drug Research and Clinical Pharmacology, 29, 657-660. (in Chinese with English abstract) [王云鹏, 肖博允, 熊文波, 吴世丹, 季爱加, 段礼新 (2018) 流式细胞术测定巴戟天基因组 大小. 中药新药与临床药理, 29, 657-660.]

Wolf DE, Steets JA, Houliston GJ, Takebayashi N (2014) Genome size variation and evolution in allotetraploid Arabidopsis kamchatica and its parents, Arabidopsis lyrata and Arabidopsis halleri. AoB Plants, 6, plu025.

Wong C, Murray BG (2012) Variable changes in genome size associated with different polyploid events in Plantago (Plantaginaceae). Journal of Heredity, 103, 711-719.

Yan HH, Martin SL, Bekele WA, Latta RG, Diederichsen A, Peng YY, Tinker NA (2016) Genome size variation in the genus Avena. Genome, 59, 209-220.

Ye LJ, Zhang ZR, Sun ZX, Tian S, Zhang ZY (2015) The determination of nuclear DNA content (2C-value) on some 
邵晨, 李耀琪, 罗奥, 王志恒, 席祯翔, 刘建全, 徐晓婷 (2021) 不同生活型被子植物功能性状与基因组大小的

关系. 生物多样性, 29, 575-585. http://www.biodiversity-science.net/CN/10.17520/biods.2020450

pepresentative genus and species of Magnoliaceae. Plant Diversity and Resources, 37, 605-610. (in Chinese with English abstract) [叶林江, 张志荣, 孙志霞, 田双, 张志勇 (2015) 木兰科主要属种核 DNA 含量(2C-值)的检 测. 植物分类与资源学报, 37, 605-610.]

Yin YY, Zhong PS, Zhang GQ, Chen LJ, Zeng SJ, Li MH, Liu ZJ (2016) Morphological, genome-size and molecular analyses of Apostasia fogangica (Apostasioideae, Orchidaceae), a new species from China. Phytotaxa, 277, 59-67.

Younis A, Ryu KB, Co VT, Hwang YJ, Jee SO, Kim MS, Kim CK, Lim KB (2013) Analysis of chromosomes and nuclear DNA content in nine genotypes of Cymbidium. Korean Society for Floricultural Science, 21, 158-161.

Žabka M, Ďurišová L', Eliáš P, Baranec T (2018) Genome size and ploidy level among wild and cultivated Prunus taxa in Slovakia. Biologia, 73, 121-128.

Zahradníček J, Chrtek J, Ferreira MZ, Krahulcová A, Fehrer J (2018) Genome size variation in the genus Andryala (Hieraciinae, Asteraceae). Folia Geobotanica, 53, 429-447.

Zhang J, Wang Y, Ma XJ, Tan F, Li M, Li YJ (2018) Determination of chromosome ploidy and genome size of Salix matsudana based on flow cytometry. Jiangsu Agricultural Sciences, 46(22), 40-43. (in Chinese) [张健, 王芗, 马 祥建, 谈峰, 李敏, 李玉娟 (2018) 基于流式细胞术的旱柳染色体倍性与基因组大小测定. 江苏农业科学, 46(22), 40-43.]

Zhang LL, Cao B, Bai CK (2013) New reports of nuclear DNA content for 66 traditional Chinese medicinal plant taxa in China. Caryologia, 66, 375-383.

Zhang NN, Yang J, Sun WB (2014) Genome size estimation of Viburnum (Adoxaceae) species by using flow cytometry. Plant Diversity and Resources, 36, 730 -736. (in Chinese with English abstract) [张宁宁, 杨静, 孙卫邦 (2014) 利用流式细胞仪测定荚蒾属植物的基因组大小. 植物分类与资源学报, 36, 730-736.]

Zhu M, Wang YP, Xiong WB, Luo YG, Duan LX, Lu XY (2018) Genome size estimation for three Iridaceae plants by using flow cytometry. Journal of Chinese Medicinal Materials, 41, 2306-2310. (in Chinese with English abstract) [朱敏, 王云鹏, 熊文波, 罗盈光, 段礼新, 陆幸妍 (2018) 流式细胞仪测定三种㚜尾科植物基因组的大小. 中药材, 41, 2306-2310.]

Zonneveld BJM (2015) Nuclear genome sizes of 343 accessions of wild collected Haworthia and Astroloba (Asphodelaceae, Alooideae), compared with the genome sizes of Chortolirion, Gasteria and 83 Aloe species. Plant Systematics and Evolution, 301, 931-953. 
(a) $R^{2}=0.005, P=0.154$, slope $=0.539$

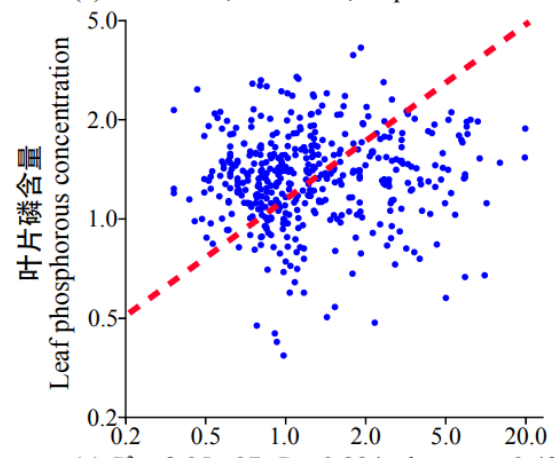

(b) $R^{2}=0.010, P=0.529$, slope $=0.506$
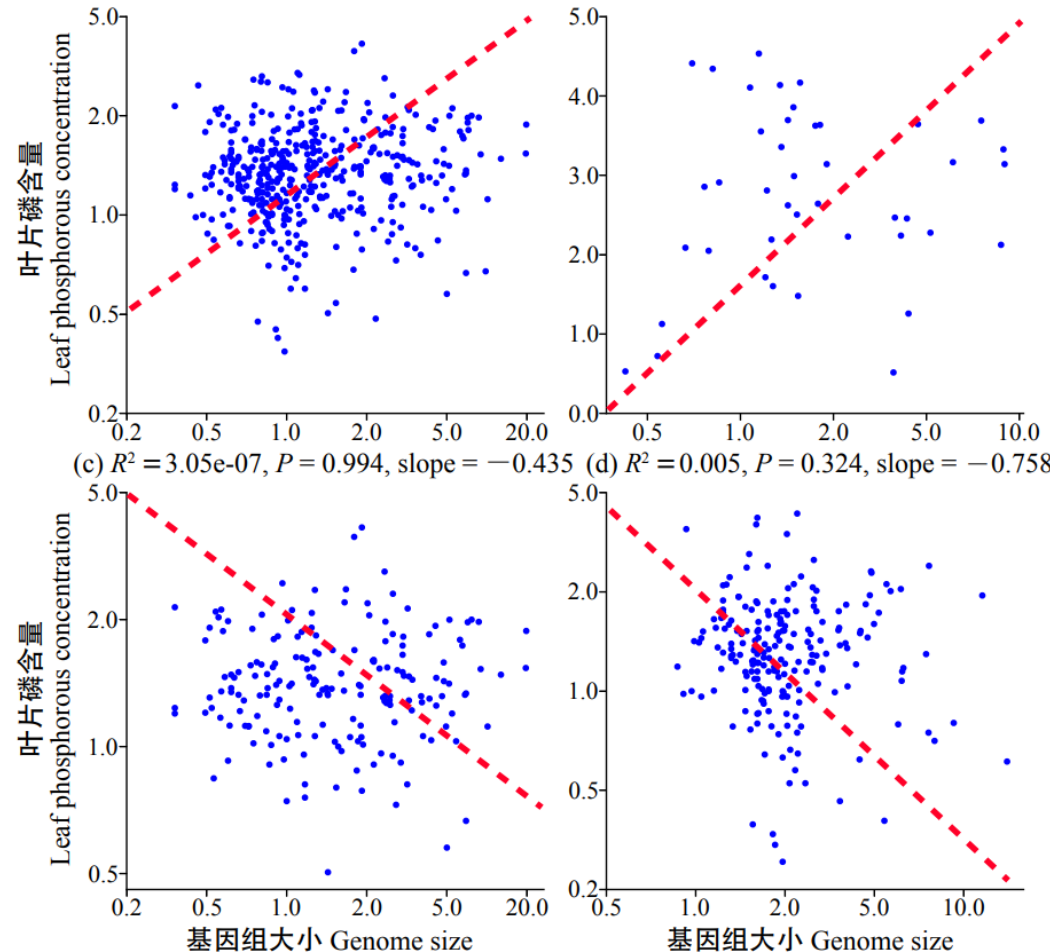

附录2 不同生活型被子植物叶片磷含量(经lg转换)与基因组大小(经lg转换)的相关性。(a)所有被子植物; (b)一 年生草本植物; (c)多年生草本植物; (d)木本植物。

Appendix 2 Correlations between genome size (lg scale) and leaf phosphorus concentration (lg scale) of different life form angiosper. (a) All angiosperms species; (b) Annual herbs; (c) Perennial herbs; (d) Woody species. 